\title{
Synthesis and Spectral Characterization of Copper(II) and Zinc(II) Complexes of An Acylhydrazone
}

\author{
M C Vineetha* and M R Prathapachandra Kurup ${ }^{\dagger}$
}

\begin{abstract}
Copper(II) and zinc(II) complexes have been synthesized by the reaction of copper(II) acetate and zinc(II) acetate with an acylhydrazone and sodium cyanate and characterized by analytical and spectral studies.
\end{abstract}

Keywords: $\mathrm{Cu}$ (II) complexes, Zn(II complexes, Acylhydrazones.

\section{Introduction}

Coordination compounds have been known for well over a century and the scientific interest in these compounds has increased dramatically. The importance of coordination complexes in our day-to-day life is increasing due to their complex structures and interesting magnetic, electronic and optical properties. Interest in coordination chemistry of acylhydrazones is associated with their wide use as drugs, photo-thermochromic compounds and precursors for organic synthesis [1-4]. In the case of acylhydrazones, the presence of the carbonyl oxygen atom promotes the formation of a chelate binding centre [5]. Acylhydrazones and their metal complexes possess pronounced biological and pharmaceutical activities as antitumor [6-8], antimicrobial [9], antituberculosis [10] and antimalarial agents [11].

Copper complexes of thiosemicarbazones show antitumoral, antiinflammatory and antibacterial activity. Some acylhydrazone

Department of Applied Chemistry, Cochin University of Science and Technology, (DAC, CUSAT),Kochi 22, India; vineethamc85@gmail.com

† (DAC, CUSAT); mrp@cusat.ac.in 
derivatives are found to be potential oral iron chelating drugs for the treatment of thalassemia. The emerging importance of $\mathrm{Zn}^{2+}$ in neurological signalling and some proposed functions in biological systems have generated an urgent demand for the development of $\mathrm{Zn}^{2+}$-specific molecular probes, and many $\mathrm{Zn}^{2+}$ fluorescent sensors have been reported, exhibiting high selectivity and sensitivity over other biologically essential metal ions in specific ranges of concentration [12-14].

In this work we report the syntheses and spectral characterization of copper and zinc complexes of 2-benzoylpyridine benzoylhydrazone (HBPB). Structure of the hydrazone is shown in Figure 1.

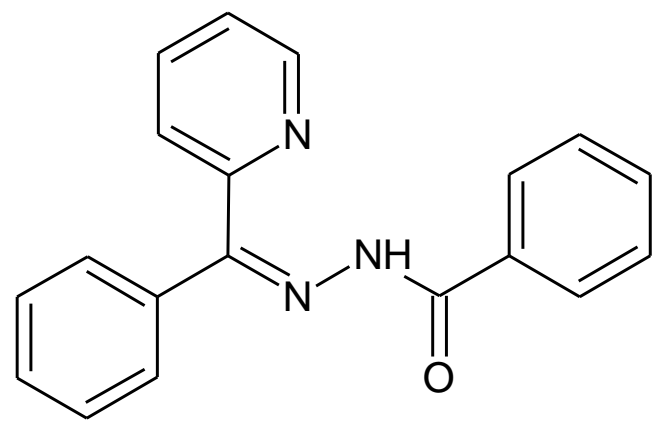

Fig 1:. 2-Benzoylpyridine benzoylhydrazone (HBPB)

\section{Results and Discussion}

\subsection{Syntheses of copper(II) and zinc(II) complexes}

The results of elemental analyses and conductivity measurements have been presented in Table 1. The results of elemental analyses show that the complexes have the molecular formulae $\left[\mathrm{Cu}_{2}(\mathrm{BPB})_{2}(\mathrm{OAc})_{2}\right](\mathbf{1}),[\mathrm{Cu}(\mathrm{BPB}) \mathrm{NCO}](\mathbf{2})$ and $\left[\mathrm{Zn}(\mathrm{BPB})_{2}\right]$ (3). The complexes are insoluble in most of the solvents. They are soluble in DMF. The molar conductivity values of the compounds in DMF show that they are non-conductors [15]. The molar conductivity values are given in Table 1. 


\begin{tabular}{|l|l|l|l|l|l|}
\hline \multirow{2}{*}{ Compound } & \multirow{2}{*}{ Color } & \multicolumn{2}{|c|}{ Elemental Anal. Found (Calcd) \% } & \multirow{2}{*}{$\lambda_{\mathrm{m}}{ }^{\#}$} \\
\cline { 3 - 6 } & & \multicolumn{1}{|c}{$\mathrm{C}$} & $\mathrm{N}$ & $\mathrm{H}$ & \\
\hline HBPB & Colorless & 75.46 & 13.98 & $5.23(5.02)$ & - \\
& & $(75.73)$ & $(13.94)$ & & \\
\hline$\left[\mathrm{Cu}_{2}(\mathrm{BPB})_{2}(\mathrm{OAc})_{2}\right](\mathbf{1})$ & Black & 60.04 & 10.54 & $3.35(4.05)$ & 2.1 \\
& & $(59.64)$ & $(9.94)$ & & \\
\hline$[\mathrm{Cu}(\mathrm{BPB}) \mathrm{NCO}](2)$ & Green & 59.41 & 13.64 & $3.14(3.48)$ & 0.9 \\
& & $(59.18)$ & $(13.80)$ & & \\
\hline$\left[\mathrm{Zn}(\mathrm{BPB})_{2}\right](\mathbf{3})$ & Yellow & 69.02 & 13.08 & $4.05(4.24)$ & 1 \\
& & $(68.52)$ & $(12.62)$ & & \\
\hline
\end{tabular}

\#molar conductivity (in mho $\mathrm{cm}^{2} \mathrm{~mol}^{-1}$ ) taken in $10^{-3} \mathrm{M}$ DMF solution.

Table 1: Elemental analyses and molar conductances

\subsection{Infrared spectral analyses}

Infra red spectral analyses confirm the presence of characteristic groups present in the compounds. Strong bands due to the $v(\mathrm{~N}-\mathrm{H})$ and $\mathrm{v}(\mathrm{C}=\mathrm{O})$ modes at 3063 and $1678 \mathrm{~cm}^{-1}$ respectively are observed in the spectrum of the acylhydrazone which suggest that the hydrazone exists in the amido form in the solid state [16-18]. A prominent band at $1571 \mathrm{~cm}^{-1}$ due to azomethine $\mathrm{v}(\mathrm{C}=\mathrm{N})$ linkage is observed in the spectrum indicating that condensation between ketone moiety of carbonyl compound and that of the hydrazide has taken place resulting in the formation of the desired ligand HBPB [19]. A comparison of the IR spectra of ligand and metal complexes shows that significant variations have occurred in the characteristic frequencies upon complexation. In all complexes, it was found that the characteristic spectral bands for $v(\mathrm{~N}-\mathrm{H})$ and $\mathrm{v}(\mathrm{C}=\mathrm{O})$ stretches of the hydrazone appearing at $3063 \mathrm{~cm}^{-1}$ and $1678 \mathrm{~cm}^{-1}$ respectively disappear on complexation, which supports the coordination via iminolate form instead of amido form, formed during tautomerization process [20,21]. In complex $\left[\mathrm{Cu}_{2}(\mathrm{BPB})_{2}(\mathrm{OAc})_{2}\right](\mathbf{1})$, the assignments of the IR spectrum (Figure 2) in the range 1300$1600 \mathrm{~cm}^{-1}$ are difficult due to the appearance of several absorption bands from both acylhydrazone and acetate. The strong band at $1640 \mathrm{~cm}^{-1}$ may be attributed to the $\mathrm{v}_{\text {as }}(\mathrm{CO})$ of $\mathrm{CH}_{3} \mathrm{COO}^{-}$group. The symmetric stretching mode for the acetate is observed at $1404 \mathrm{~cm}^{-1}$ [22]. The separation between the two peaks $(\Delta)$ is $236 \mathrm{~cm}^{-1}$. For classical carboxylate bridges $(\mathrm{Cu}-\mathrm{O}-\mathrm{C}-\mathrm{O}-\mathrm{Cu})$, the value of $\Delta$ is usually $\sim 180 \mathrm{~cm}^{-1}$. The $\Delta$ value of complex is higher than the 
classical bridges but lower than the monodentate. It substantiates the non-symmetric bridging mode of the carboxylate in the complex [23]. The presence of unsymmetrical mono-atomic acetate oxygen bridge in complex $\mathbf{1}$ is also confirmed from single crystal XRD [24]. A new band appears at $1370 \mathrm{~cm}^{-1}$ due to $\mathrm{v}(\mathrm{C}-\mathrm{O})$ mode indicating the coordination in the enolic form [25]. The strong absorption band at $1571 \mathrm{~cm}^{-1}$ ascribed to the imine stretching frequency of the uncoordinated ligand, shifts towards lower frequency on complexation with the metal, suggesting coordination to the metal through imine nitrogen $[26,27]$. On complexation a new band appeared at $1584 \mathrm{~cm}^{-1}$ due to $\mathrm{v}(\mathrm{C}=\mathrm{N})[28,29]$.

In the complex [Cu(BPB)NCO] (2), the azomethine band appears at $1505 \mathrm{~cm}^{-1}$. A new band due to $\mathrm{v}(\mathrm{C}=\mathrm{N})$ at $1596 \mathrm{~cm}^{-1}$ indicates tautomerization and coordination of the hydrazone in the enolate form. A band at $1357 \mathrm{~cm}^{-1}$ indicates the coordination of $\mathrm{C}-\mathrm{O}$ group. The $v(\mathrm{~N}-\mathrm{N})$ stretching band appears at $1143 \mathrm{~cm}^{-1}$. The IR spectrum exhibits a strong peak at $2188 \mathrm{~cm}^{-1}$, which indicates the presence of $-\mathrm{NCO}$ group [16]. The spectrum of [Cu(BPB)NCO] (2) is shown in Figure 3. In the complex $\left[\mathrm{Zn}(\mathrm{BPB})_{2}\right](3)$ a band at $1585 \mathrm{~cm}^{-1}$ corresponds to the newly formed $\mathrm{C}=\mathrm{N}$ bond. A peak at $1345 \mathrm{~cm}^{-1}$ corresponding to $\mathrm{v}(\mathrm{C}-\mathrm{O})$ indicate the oxygen coordination. The $\mathrm{v}(\mathrm{N}-\mathrm{N})$ band appears at $1142 \mathrm{~cm}^{-1}$.

\begin{tabular}{|l|l|l|l|l|l|l|}
\hline Compound & $\mathrm{v}(\mathrm{C}=\mathrm{O})$ & $\mathrm{v}(\mathrm{N}-\mathrm{H})$ & $\mathrm{v}(\mathrm{C}=\mathrm{N})$ & $\mathrm{v}(\mathrm{C}=\mathrm{N})^{\mathrm{a}}$ & $\begin{array}{l}\mathrm{v}(\mathrm{C}- \\
\mathrm{O})\end{array}$ & $\mathrm{v}(\mathrm{N}-\mathrm{N})$ \\
\hline $\mathrm{HBPB}$ & 1678 & 3063 & 1571 & --- & --- & --- \\
\hline$\left[\mathrm{Cu}_{2}(\mathrm{BPB})_{2}(\mathrm{OAc})_{2}\right](\mathbf{1})$ & ---- & ---- & 1500 & 1584 & 1370 & 1131 \\
\hline$[\mathrm{Cu}(\mathrm{BPB}) \mathrm{NCO}](2)$ & ---- & --- & 1505 & 1596 & 1357 & 1143 \\
\hline$\left[\mathrm{Zn}(\mathrm{BPB})_{2}\right](3)$ & --- & --- & 1508 & 1585 & 1345 & 1142 \\
\hline
\end{tabular}

${ }^{\text {a }}$ Newly formed $\mathrm{C}=\mathrm{N}$ bond

Table 2: Infrared spectral data $\left(\mathrm{cm}^{-1}\right)$ of the hydrazones and their copper(II) and zinc(II) complexes 


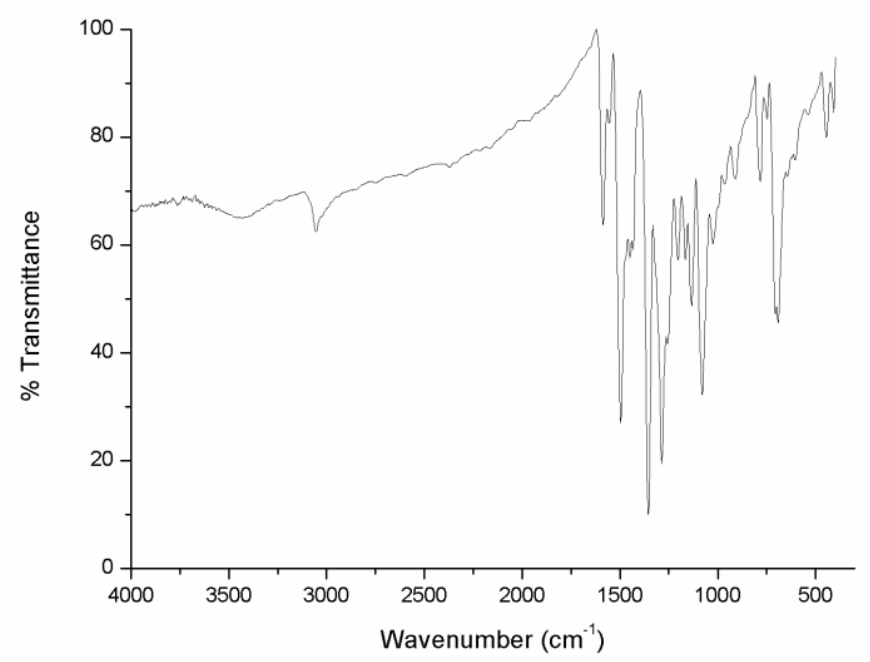

Figure 2: IR spectrum of complex $\left[\mathrm{Cu}_{2}(\mathrm{BPB})_{2}(\mathrm{OAc})_{2}\right](\mathbf{1})$.

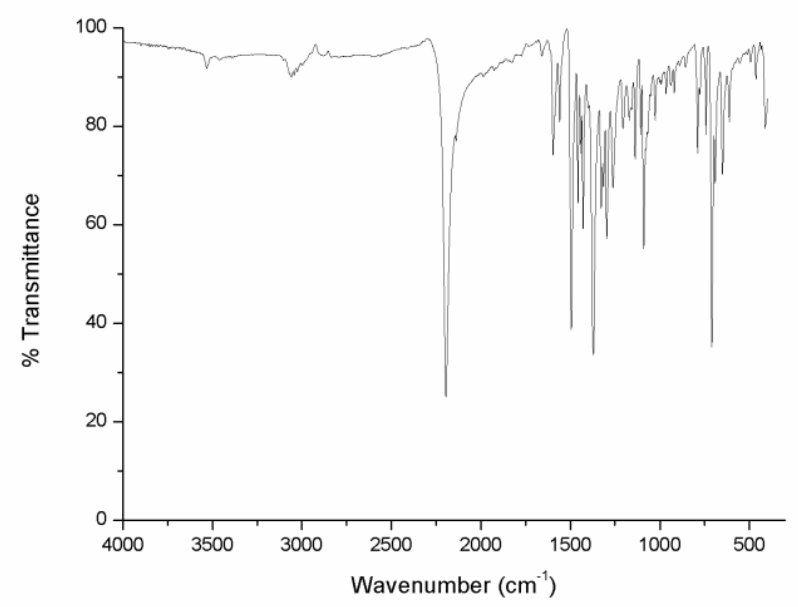

Figure 3: IR spectrum of complex [Cu(BPB)NCO] (2).

\subsection{Electronic Spectral Analyses}

The electronic spectra of the complexes were recorded in DMF solution. The $\mathrm{Cu}$ (II) complexes with $d^{9}$ configuration is expected to experience Jahn-Teller distortion which leads to the further splitting of the ${ }^{2} E_{\mathrm{g}}$ and ${ }^{2} T_{\mathrm{g}}$ levels and give rise to three spin allowed 
transitions viz. ${ }^{2} A_{1 \mathrm{~g}} \leftarrow{ }^{2} B_{1 \mathrm{~g}},{ }^{2} B_{2 \mathrm{~g}} \leftarrow{ }^{2} B_{1 \mathrm{~g}}$ and ${ }^{2} E_{\mathrm{g}} \leftarrow{ }^{2} B_{1 \mathrm{~g}}$ which occur in the ranges $12000-17000,15500-18000$ and $17000-20000 \mathrm{~cm}^{-1}$ respectively. But in practice it is difficult to resolve them into separate bands due to the low energy difference between these energy levels.

The presence of broad band in all complexes in the range 14630$14380 \mathrm{~cm}^{-1}$ can be assigned to $d-d$ transition. The bands observed in the region $24980-25450 \mathrm{~cm}^{-1}$ are mainly due to the phenoxy $\mathrm{O} \rightarrow \mathrm{Cu}(\mathrm{II})$ charge transfer transitions [30-32]. The remaining bands correspond to the intraligand transitions. Due to filled $d$ orbitals, $d$ - $d$ transitions are not expected in the case of Zn(II) complexes. But these complexes are yellow colored and the colors of the complexes are attributed to metal to ligand charge transfer transitions. Here MLCT bands were observed. The intraligand transitions were found to be slightly shifted during complexation. Table 3 summarises the electronic absorption data of the complexes.

\begin{tabular}{|l|l|l|l|}
\hline Compound & $\begin{array}{l}\text { Intraligand } \\
\text { Transitions }\end{array}$ & LMCT/MLCT & $d-d$ \\
\hline \hline $\mathrm{HBPB}$ & $31050,36900,42920$ & --- & --- \\
\hline $\begin{array}{l}{\left[\mathrm{Cu}_{2}(\mathrm{BPB})_{2}(\mathrm{OAc})_{2}\right]} \\
(1)\end{array}$ & 35380 & 25090 & 14630 \\
\hline \hline$[\mathrm{Cu}(\mathrm{BPB}) \mathrm{NCO}](2)$ & 30050 & 24980 & 14380 \\
\hline$\left[\mathrm{Zn}(\mathrm{BPB})_{2}\right](3)$ & 34540,42110 & 25450 & --- \\
\hline
\end{tabular}

Table 3: Electronic spectral assignments $\left(\mathrm{cm}^{-1}\right)$ of $\mathrm{Cu}$ (II) and $\mathrm{Zn}$ (II) complexes

\section{Experimental}

Copper(II) acetate, benzoic hydrazide, 2-benzoylpyridine, sodium cyanate, zinc acetate were of Analar quality and were used without further purification.

\subsection{Syntheses of the complexes}

1) Preparation of $\left[\mathrm{Cu}_{2}(\mathrm{BPB})_{2}(\mathrm{OAc})_{2}\right](\mathbf{1})$

$\mathrm{Cu}(\mathrm{OAc})_{2} \cdot \mathrm{H}_{2} \mathrm{O}(0.199 \mathrm{~g}, 1 \mathrm{mmol})$ dissolved in methanol was added to a methanolic solution of HBPB $(0.301 \mathrm{~g}, 1 \mathrm{mmol})$. The reaction mixture was refluxed for 3 hours. The solution was kept for two days for evaporation. Black shining crystals were separated, 72 
Cr(II) and Zn(II) Complexes of Acylhydrazone Mapana J Sci, 12, 2,(2013)

filtered, washed with methanol followed by ether and dried over $\mathrm{P}_{4} \mathrm{O}_{10}$ in vacuo (Scheme 1 ).
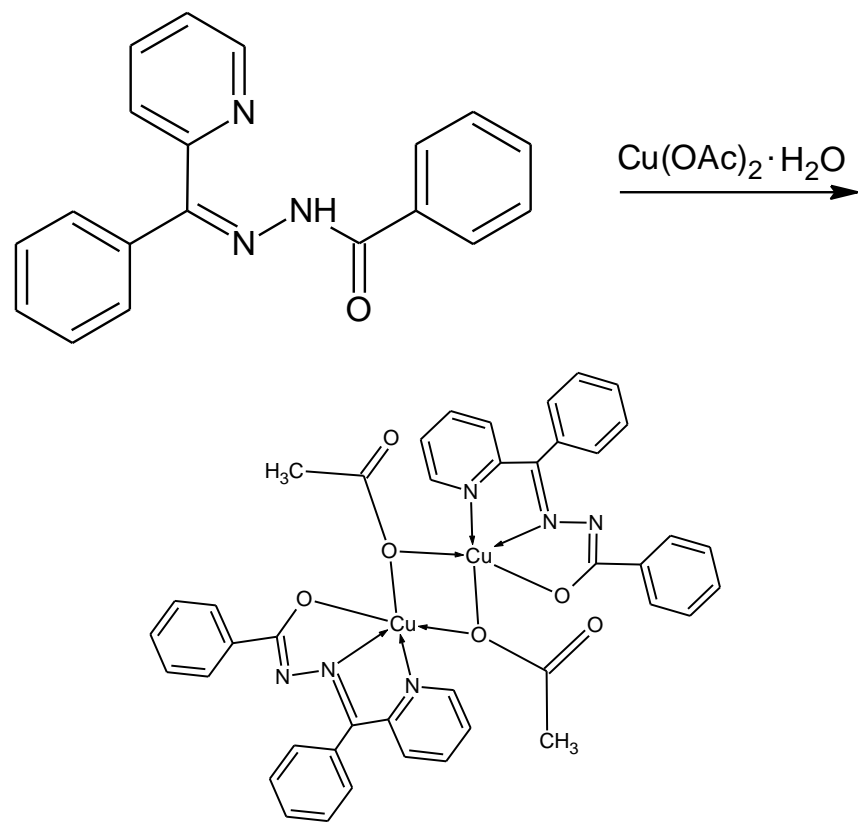

Scheme 1: Preparation of $\left[\mathrm{Cu}_{2}(\mathrm{BPB})_{2}(\mathrm{OAc})_{2}\right]$

2) Preparation of $[\mathrm{Cu}(\mathrm{BPB}) \mathrm{NCO}](2)$

To a methanolic solution of HBPB (0.301 g, $1 \mathrm{mmol})$, sodium cyanate $(0.065 \mathrm{~g}, 1 \mathrm{mmol})$ dissolved in methanol was added and refluxed for half an hour. Then a methanolic solution of $\mathrm{Cu}(\mathrm{OAc})_{2} \cdot \mathrm{H}_{2} \mathrm{O}(0.199 \mathrm{~g}, 1 \mathrm{mmol})$ was added and refluxed for 3 hours. Dark green precipitate obtained was filtered, washed with methanol, followed by ether and dried over $\mathrm{P}_{4} \mathrm{O}_{10}$ in vacuo (Scheme 2). 


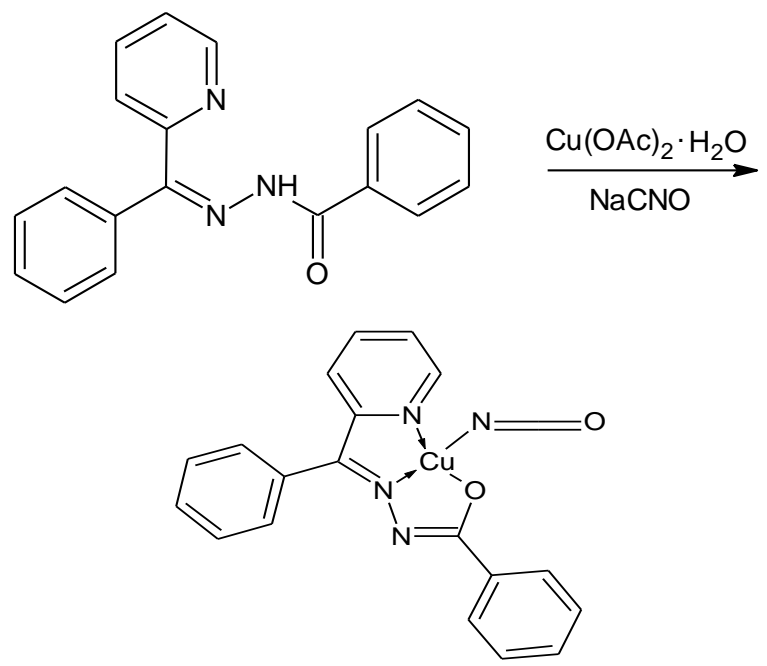

Scheme 2: Preparation of [Cu(BPB)NCO]

3) Preparation of $\left[\mathrm{Zn}(\mathrm{BPB})_{2}\right](3)$

To a methanolic solution of HBPB $(0.602 \mathrm{~g}, 2 \mathrm{mmol})$, a methanolic solution of $\mathrm{Zn}\left(\mathrm{CH}_{3} \mathrm{COO}\right)_{2} \cdot 2 \mathrm{H}_{2} \mathrm{O}(0.219 \mathrm{~g}, 1 \mathrm{mmol})$ was added and refluxed for 3 hours. Yellow precipitate that was obtained was filtered, washed with methanol, followed by ether and dried over $\mathrm{P}_{4} \mathrm{O}_{10}$ in vacuo (Scheme 3).

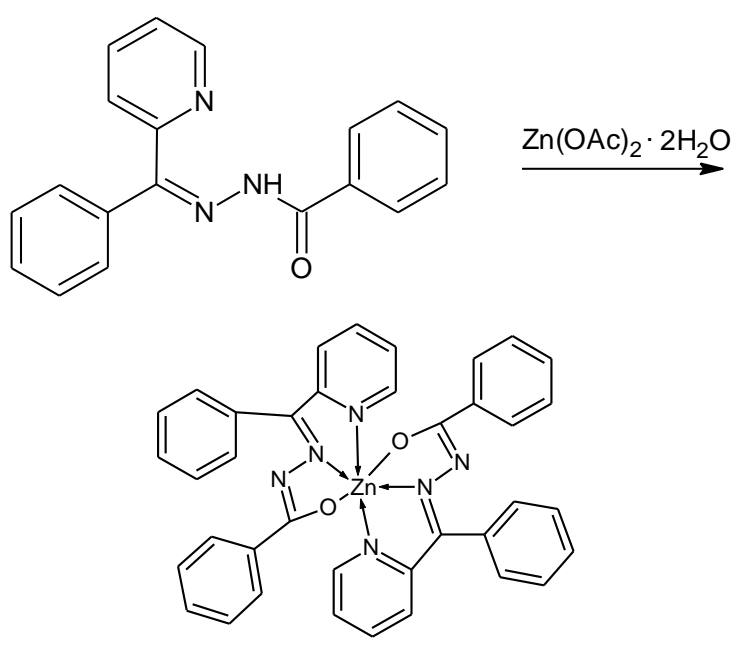

Scheme 3: Preparation of $\left[\mathrm{Zn}(\mathrm{BPB})_{2}\right.$ 


\subsection{Analytical Method}

Elemental analyses of complexes were performed on a Vario EL III CHNS analyzer at SAIF, Kochi, India. The molar conductances of the complexes in DMF $\left(10^{-3} \mathrm{M}\right)$ solution were measured at $298 \mathrm{~K}$ with a Systronic model 303 direct-reading conductivity bridge. IR spectra were recorded on a JASCO FT/IR-4100 Fourier Transform Infrared Spectrometer using $\mathrm{KBr}$ pellets in the range 4000-400 $\mathrm{cm}^{-1}$. Electronic spectra were recorded in DMF on a Spectro UV-vis Double Beam UVD-3500 spectrometer in the range 200-900 nm range.

\section{Conclusion}

Copper and zinc complexes of an acylhydrazone were synthesized and characterized. The elemental analyses data clearly show that the complexes have the empirical formula $[\mathrm{Cu}(\mathrm{BPB})(\mathrm{OAc})]$, $[\mathrm{Cu}(\mathrm{BPB}) \mathrm{CNO}]$ and $[\mathrm{Zn}(\mathrm{BPB})]$, where BPB stands for deprotonated ligand. These complexes are characterized by IR and UV-visible measurements. Complex $\left[\mathrm{Cu}_{2}(\mathrm{BPB})_{2}(\mathrm{OAc})_{2}\right](\mathbf{1})$ is a mono-atomic acetate oxygen bridged dimer.

\section{Acknowledgement}

The authors are thankful to the Sophisticated Analytical Instrument Facility, Cochin University of Science \& Technology, Kochi-22 for providing analytical and spectral data. MCV thanks the Council of Scientific and Industrial Research, New Delhi, India for the award of Junior Research Fellowship. MRPK thanks the University Grants Commission, New Delhi for UGC-BSR one-time grant to faculty.

\section{References}

[1] E. Shmidt, Hydrazine and its Derivatives: Preparation, Properties, Applications, 2nd ed., Wiley, New York 2001.

[2] P. V. Bernhardt, P. Chin, and D. R. Richardson, "Unprecedented oxidation of a biologically active aroylhydrazone chelator catalyzed by iron(III): serendipitous identification of diacylhydrazine ligands with high iron chelation efficacy," J. Biol. Inorg. Chem., vol. 6, pp. 801, 2001. 
[3] V. Kogan, V. Zelentsov, G. Larin, and V. Lhukov, Complexes of Transitional Metals with Hydrazones, Nauka, Moscow, 1990.

[4] U. Ragnarsson, "Synthetic methodology for alkyl substituted hydrazines," Chem. Soc. Rev., vol. 30, pp. 205, 2001. doi: 10.1039/B010091A

[5] S. S. Tandon, S. Chander, and L. K. Thompson, "Ligating properties of tridentate Schiff base ligands, 2-[[(2-pyridinylmethyl)imino]methyl] phenol (HSALIMP) and 2-[[[2-(2pyridinyl)ethyl]imino]methyl]phenol (HSALIEP) with zinc(II), cadmium(II), nickel(II) and manganese(III) ions. X-ray crystal structures of the $\left[\mathrm{Zn}(\mathrm{SALIEP})\left(\mathrm{NO}_{3}\right)\right]_{2}$ dimer, $\left[\mathrm{Mn}(\mathrm{SALIEP})_{2}\right]\left(\mathrm{ClO}_{4}\right)$, and $\left[\mathrm{Zn}(\mathrm{AMP})_{2}\left(\mathrm{NO}_{3}\right)_{2}\right]$," Inorg. Chim. Acta, vol. 300-302, pp. 683, 2000. doi:10.1016/S0020-1693(00)00010-4

[6] N. Terzioglu and A. Gürsoy, "Synthesis and anticancer evaluation of some new hydrazone derivatives of 2,6-dimethylimidazo[2,1b][1,3,4]thiadiazole-5- carbohydrazide," Eur. J. Med. Chem., vol. 38, pp. 781, 2003. doi:10.1016/S0223-5234(03)00138-7

[7] M. T. Cocco, C. Congiu, V. Lilliu, and V. Onnis, "Synthesis and in vitro antitumoralactivity of new hydrazinopyrimidine-5-carbonitrile derivatives," Bioorg. Med. Chem., vol. 14, pp. 366, 2006. doi:10.1016/j.bmc.2005.08.012

[8] J. Easmon, G. Puerstinger, T. Roth, H. H. Fiebig, M. Jenny, W. Jaeger, G. Heinisch, and J. Hofmann, "2-Benzoxazolyl and 2-benzimidazolyl hydrazones derived from 2-acetylpyridine: a novel class of antitumor agents," Int. J. Cancer, vol. 94, pp. 89, 2001. DOI: 10.1002/ijc.1427

[9] P. Vicini, F. Zani, P. Cozzini, and I. Doytchinova, "Hydrazones of 1,2benzisothiazole hydrazides: synthesis, antimicrobial activity and QSAR investigations," Eur. J. Med. Chem., vol. 37, pp. 553, 2002.

[10] J. Patole, U. Sandbhor, S. Padhye, D. N. Deobagkar, C. E. Anson, and A. Powell, "Structural chemistry and in vitro antitubercular activity of acetylpyridine benzoyl hydrazone and its copper complex against mycobacterium smegmatis," Bioorg. Med. Chem. Lett., vol. 13, pp. 51, 2003. doi:10.1016/S0960-894X(02)00855-7

[11] A. Walcourt, M. Loyevsky, D. B. Lovejoy, V. R. Gordeuk, and D. R. Richardson, "Novel aroylhydrazone and thiosemicarbazone iron chelators with anti-malarial activity against chloroquine-resistant and -sensitive parasites," Int. J. Biochem. Cell Biol., vol. 36, pp. 401, 2004.

[12]B. L. Vallee, and K. H. Falchuk, "The biochemical basis of zinc physiology," Physiol. Rev., vol. 73, pp. 79, 1993. 
Cr(II) and Zn(II) Complexes of Acylhydrazone Mapana J Sci, 12, 2,(2013)

[13] C. J. Chang, E. M. Nolan, J. Jaworski, S.C. Burdette, M. Sheng, and S. J. Lippard, "Bright fluorescent chemosensor platforms for imaging endogenous pools of neuronal zinc," Chem. Biol., vol. 11, pp. 203, 2004. doi:10.1016/j.chembiol.2004.01.017

[14] A. Ajayaghosh, P. Carol, and S. Sreejith, "A ratiometric fluorescence probe for selective visual sensing of $\mathrm{Zn}^{2+}$," J. Am. Chem. Soc., vol. 127, pp. 14962, 2005. doi: 10.1021/ja054149s

[15]W. J. Geary, "The use of conductivity measurements in organic solvents for the characterisation of coordination compounds," Coord. Chem. Rev., vol. 7, pp. 81, 1971. doi:10.1016/S0010-8545(00)80009-0

[16]K. Nakamoto, Infrared and Raman Spectra of Inorganic and Coordination Compounds, 5th ed., Wiley, New York, 1997.

[17]N. Mathew, M. Kuriakose, E. B. Seena, and M. R. P. Kurup, “2'-(2Hydroxy-4-methoxybenzylidene)nicotinohydrazide monohydrate," Acta Cryst. E, vol. 63, pp. 2190, 2007. doi:10.1107/S1600536807014808

[18]Y. Nair, M. Sithambaresan, and M. R. P. Kurup, "N'-[(E)-(3Fluoropyridin-2-yl) methylidene]benzohydrazide monohydrate," Acta Cryst. E, vol. 68, pp. 2709, 2012. doi:10.1107/S1600536812035179

[19]M. Carcelli, P. Cozzini, T. Maccagni, C. Pelizzi, and L. Righi, "Synthetic routes to mono-and bi-copper hydrazone complexes uncovered by computer simulation," Inorg. Chim. Acta, vol. 303, pp. 238, 2000. doi:10.1016/S0020-1693(00)00040-2

[20] P. B. Sreeja, K. R. Sunaja Devi, K. Vinayakumar, and M. R. P. Kurup, "Synthesis, spectral and magnetic properties of ternary nickel(II) complexes with acid hydrazones and heterocyclic Bases," Mapana J. Sci. vol. 11, pp. 45, 2012.

[21] M. F. Iskander, T. E. Khalil, R. Werer, W. Haase, I. Svoboda, and H. Fuess, "Synthesis, reactivity and magnetochemical studies on copper(II) complexes derived from N-salicylidenearoylhydrazines. Xray structure of [mononitratoOO $(-1)(\mathrm{N}$ salicylidenatobenzoylhydrazine)ONO (-1)]copper (II) monohydrate," Polyhedron, vol. 19, pp. 949, 2000. doi:10.1016/S0277-5387(00)00340-5

[22] B. Sarkar, M. G. B. Drew, M. Estrader, C. Diaz, and A. Ghosh, "CuII acetate complexes involving N,N,O donor Schiff base ligands: monoatomic oxygen bridged dimers and alternating chains of the dimers and $\mathrm{Cu}_{2}(\mathrm{OAc})_{4}, "$ Polyhedron, vol. 27, pp. 2625, 2008. doi:10.1016/j.poly.2008.05.004

[23] P. Mukherjee, O. Sengupta, M. G. B. Drew, and A. Ghosh, "Anion directed template synthesis of $\mathrm{Cu}(\mathrm{II})$ complexes of a $\mathrm{N}, \mathrm{N}, \mathrm{O}$ donor 
mono-condensed schiff base ligand: a molecular scaffold forming highly ordered H-bonded rectangular grids," Inorg. Chim. Acta, vol. 362, pp. 3285, 2009. doi:10.1016/j.ica.2009.02.041

[24] M. C. Vineetha, M. Sithambaresan, J. M. Jacob, and M. R. P. Kurup, “Di- $\mu$-acetato- $\quad \mathrm{K}^{4} \mathrm{O}: \mathrm{O}-\mathrm{bis}(\{\mathrm{N}$ ’-[(E)-phenyl(pyridin-2-ylкN)methylidene] benzohydrazidato-k²N',O\}copper(II))," Acta Cryst. E, vol. 68, pp. 1086, 2012. doi:10.1107/S1600536812031467

[25] R. C. Maurya, and S. Rajput, “Neutral dioxovanadium(V) complexes of biomimet hydrazones ONO donor ligands of bioinorganic and medicinal relevance: synthesis via air oxidation of bis(acetylacetonato)oxovanadium(IV), characterization, biological activity and 3D molecular modelling," J. Mol. Struct., vol. 833, pp.133, 2007. doi:10.1016/j.molstruc.2006.09.022

[26]P. Noblia, E. J. Baran, L. Otero, P. Draper, H. Cerecetto, M. Gonzalez, O. E. Piro, E. E. Castellano, T. Inohara, Y. Adachi, H. Sakurai, and D. Gambino, "New vanadium(V) complexes with salicylaldehyde semicarbazone derivatives: synthesis, characterization, and in vitro insulin-mimetic activity - crystal structure of $\left[\mathrm{VvO}_{2}\right.$ (salicylaldehyde semicarbazone)]," Eur. J. Inorg. Chem., vol. 2004 pp. 322, 2004. doi:10.1002/ejic.200300421

[27]H. Yin, "The new three-dimensional supramolecule bis $\{[\mu]-2-[(4-$ hydroxybenzoyl)hydrazonomethyl]phenolato\} bis[aquacopper(II)] dinitrate," Acta Cryst. C, vol. 64, pp. 324, 2008. doi:10.1107/S0108270108026401

[28]N. A. Mangalam, and M. R. P. Kurup, "Synthesis and spectral investigations of vanadium(IV/V) complexes derived from an ONS donor thiosemicarbazone ligand," Spectrochim. Acta Part A Molecular and Biomolecular spectroscopy, vol. 71, pp. 2040, 2009. doi:10.1016/j.saa.2008.07.043

[29] J. Chakraborty, S. Thakurta, G. Pilet, D. Luneau, and S. Mitra, “A novel tetra $\left(\mu_{3}\right.$-phenoxo) bridged copper(II) Schiff base complex containing a $\mathrm{Cu}_{4} \mathrm{O}_{4}$ cubane core: synthesis, structural aspects and magneto-structural correlations," Polyhedron, vol. 28, pp. 819, 2009. doi:10.1016/j.poly.2008.12.018

[30]M. Singh, V. Aggarwal, U. P. Singh, and N. K. Singh, "Synthesis, spectroscopic and crystal structure investigation of $\left[\mathrm{Cu}(\text { bzsmp })_{2} \mathrm{Cl}_{2}\right] ;\{$ bzsmp $=$ 2-benzylsulfanyl-5-(2-methoxyphenyl)1,3,4-oxadiazole\}: cyclization of $\mathrm{N}^{2}$-[bis(benzylsulfanyl)methylene]- 2methoxybenzohydrazide to 2-benzylsulfanyl-5-(2-methoxyphenyl)1,3,4-oxadiazole during complexation," Polyhedron, vol. 28, pp. 195, 2009. doi:10.1016/j.poly.2008.10.016 
Cr(II) and Zn(II) Complexes of Acylhydrazone Mapana J Sci, 12, 2,(2013)

[31] A. B. P. Lever, Inorganic Electronic Spectroscopy, 2nd ed., Elsevier, Amsterdam, 1984.

[32]R. Li, B. Moubaraki, K. S. Murray, and S. Brooker, "Monomeric, dimeric and 1D chain polymeric copper(II) complexes of a pyrrolecontaining tridentate Schiff-base ligand and its 4-brominated analogue," Dalton Trans., pp. 6014, 2008. doi:10.1039/b808845d 